\title{
Acrylic Based Individual Ocular Prothesis
}

\author{
A Case Report \\ Fahma Kunsputri ${ }^{1, *}$ Haryo Dipoyono ${ }^{2, *}$ Endang Wahyuningtyas ${ }^{3}$
}

\author{
${ }^{1}$ Resident Department of Prosthodontics, Faculty of Dentistry Gadjah Mada University Yogyakarta \\ ${ }^{2,3}$ Lecturer Department of Prosthodontics, Faculty of Dentistry Gadjah Mada University Yogyakarta \\ *Corresponding author. Email: aldihyahfahma@yahoo.co.id
}

\begin{abstract}
Background: Ocular defects due to eye enucleation may affect patient psychologically. Individual ocular prothesis have several advantages compared to stock ocular prothesis. Acrylic based is one of the most used individual ocular prothesis. Objective: To describe a simple method of fabricating ocular prothesis by combination of an old custom prothesis for precise and better treatment. Material and Methods: Patient management was started from subjective and objective examinations, impression with light body using existing ocular prothesis was taken, wax pattern had made as a base of sclera, shade guide was taken with the help of tooth shade guide. The next procedure was attaching the iris and pupil on the acrylic based sclera using transparent graph grid. Photography of contralateral eye was taken for mimicking iris color for aesthetical and natural individual ocular prothesis Results: The results were satisfactory with acceptable in aesthetic, retention and stabilization Conclusion: The acrylic based custom ocular prothesis can help to restoring the eye defect after enucleation with good aesthetics, retention and stabilization.
\end{abstract}

Keywords: Eye enucleation, Ocular impression, Individual ocular prothesis

\section{INTRODUCTION}

The eye plays a vital role as one of the six senses in human. Eyes are the centre of facial expression and the organ of vision. Trauma, injury and congenital defect can cause loss of an eye [1]. Physical, social and psychological can be impacted because of losing facial structures [2]. Rehabilitation on this defect is challenging because we must produce the same visualization in colour, shape, contour and orientation to get realistic appearance $[1,3,4]$.

Nowadays, ocular prothesis made from acrylic is still popular (5). An ocular prothesis can be a stock and custom made prothesis, or individual prothesis. This individual prothesis provides a better movement, provides more comfort, improves tissue health, improves fitness, is cheaper and enhancing aesthetic better than stock prothesis [2,6,7]. This case report describes a simple method of fabricating ocular prothesis by combining an old custom prothesis for precise and better treatment.

\section{CASE REPORT}

A 9 years old girl came to the department of prosthodontics Universitas Gadjah Mada complaining about her ocular prothesis that was not fit enough, there was a colour changing, and a lot of eye debris and fluid came out even when it had always been cleaned (Fig.1). Case history revealed that the patient had undergo enucleation surgery when she was at kindergarten. She even made this custom made ocular prothesis 1 year ago. Upon objective examination the mucosa was healthy, eyelid muscle was healthy and the depth of the sulcus was sufficient enough to retain the prosthesis. A new custom-made individual prothesis was planned.

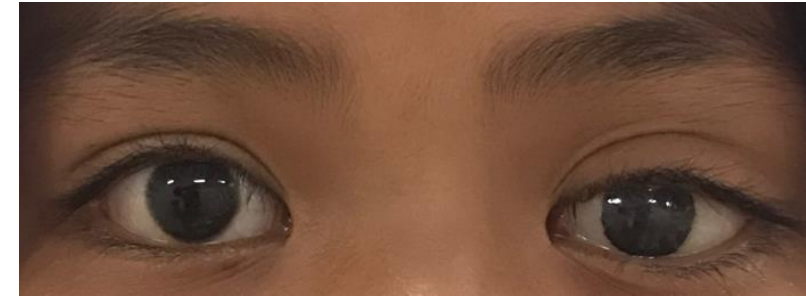

Fig. 1. Preoperative view with her old custom prothesis

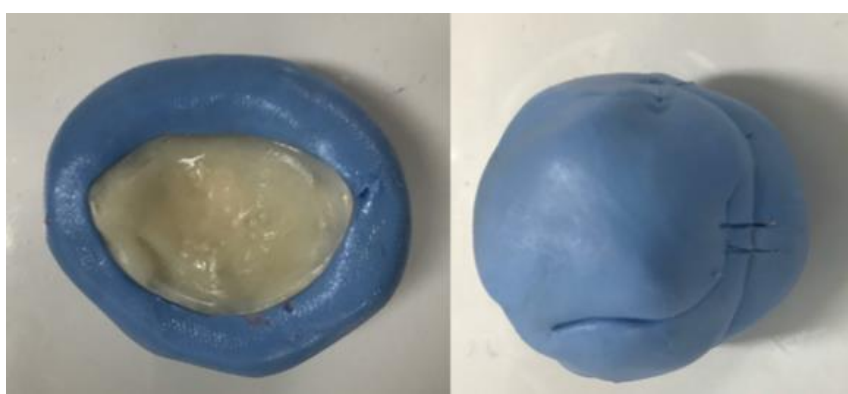

Fig. 2. Duplicating the old prothesis for custom tray.
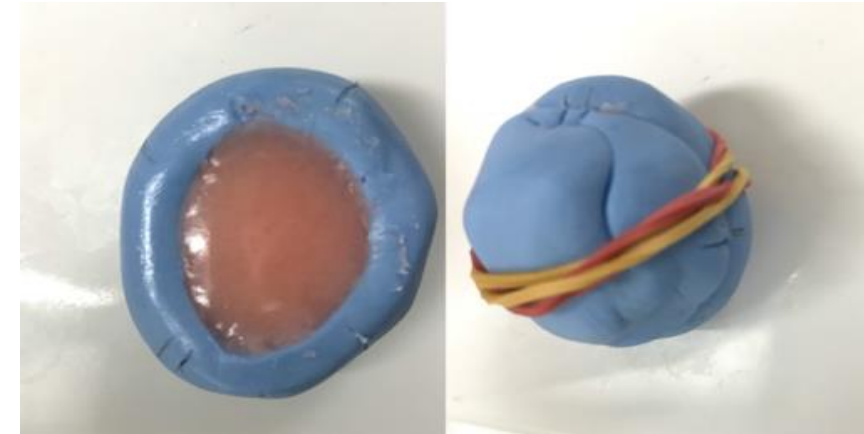

Fig. 3. Fabricated custom tray using self cure acrylic. 
Custom tray was fabricated by duplicating the old prothesis with putty and the impression was marked (Fig 2). The self-cure acrylic was inserted on that impression to make a custom tray prothesis (Fig 3). A thin tube was attached to serve as a handle of the tray. Petroleum jelly was applied around the skin to prevent the impression sticking to the eyelashes. Impression of the socket was made with light body polyvinyl siloxane. The impression material was inserted gently to the sulcus to avoid any bubbles. Patient was asked to perform eye movement in all directions so the impression material had a proper flow to the eye sulcus. Impression was checked to make sure all part of the sulcus were recorded (Fig 4). Cast was poured in two parts with the second part being poured after applying lubricant.

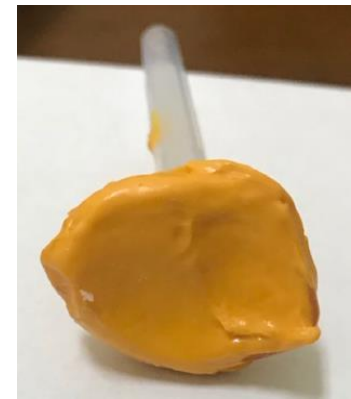

Fig. 4. Impression of the sulcus with light body polyvinyl siloxane

Wax fabrication was fabricated on dental laboratory. After fabrication, it was tried inside patient's socket and checked for harmonization on size, comfort, and retention by performing the functional movement of the eye (Fig 5). Shade of the sclera was taken with help of the tooth shade guide (Fig. 6). The wax pattern was molded, dewaxed, and packed with acrylic heat cure resin tooth coloured. Dewaxing and packaging was done after matching the shade of sclera.

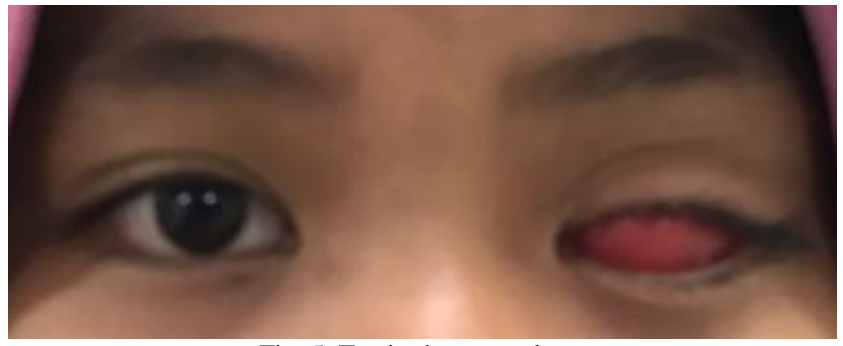

Fig. 5. Try-in the wax sclera.

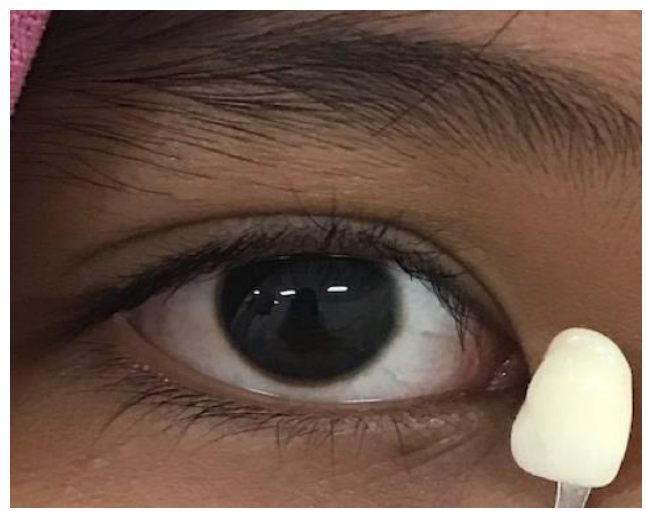

Fig. 6. Color matching with the help of tooth shade guide

The next appointment, we tried the acrylic blanked sclera. This sclera should be harmonize with the other eye, comfortable and should not be irritating the sulcus (Fig. 7). On this visit, the iris and pupil location was marked. A transparent graphic grid was used to determine the position of the centre of the pupil. A vertical midline was marked passing through glabella (Fig. 8). The distance from the contralateral eye and the centre of the pupil was measured. The facial markings then transferred to the grid template by placing it on patients face. These markings were transferred to the blank sclera. The central pupil must be certain first then we measured the iris diameter with sliding calliper and drawing them on acrylic based sclera (Fig. 9). The iris, pupil and blood vessel shade were matched with contralateral eye using photograph (Fig 10).

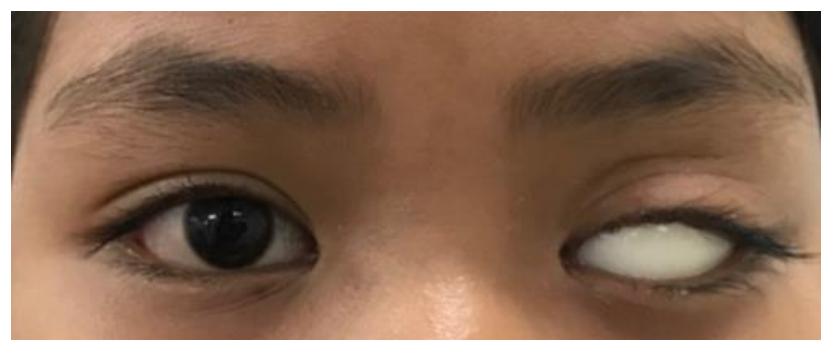

Fig. 7. The Acrylic blank sclera.

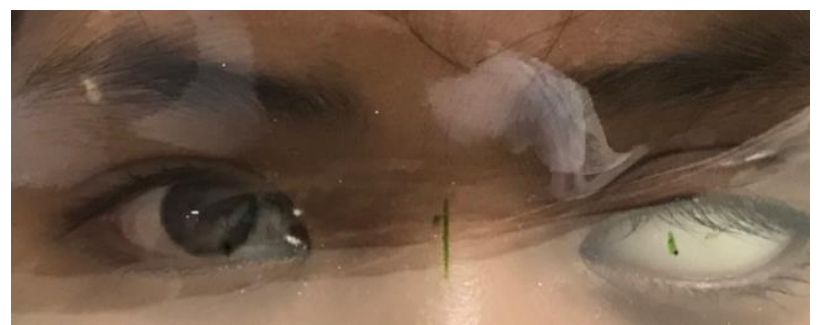

Fig. 8. Tracing central pupil with transparent graphic grid.

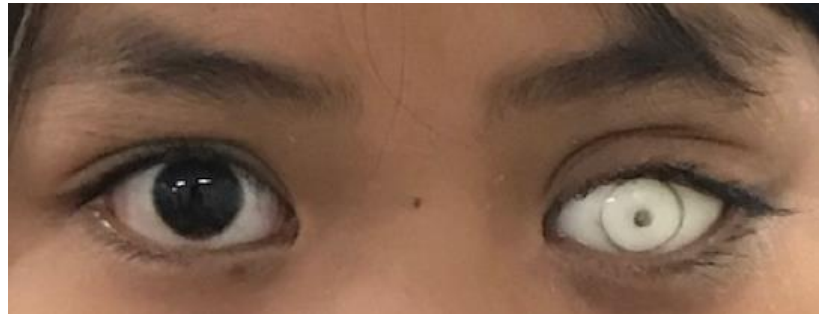

Fig. 9. Drawing the iris and pupil.

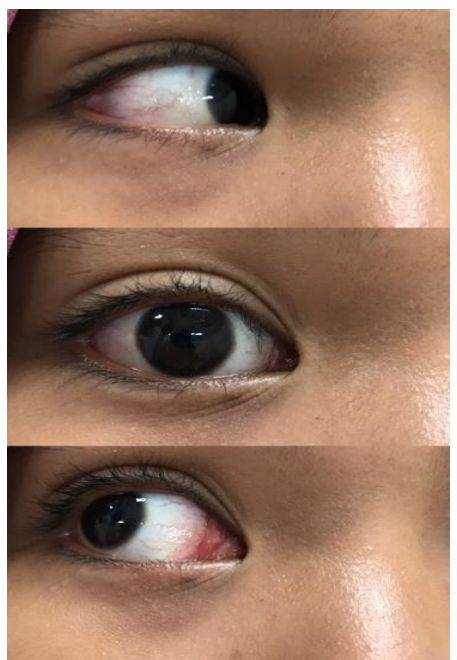

Fig. 10. Photograph the color of natural eye. 


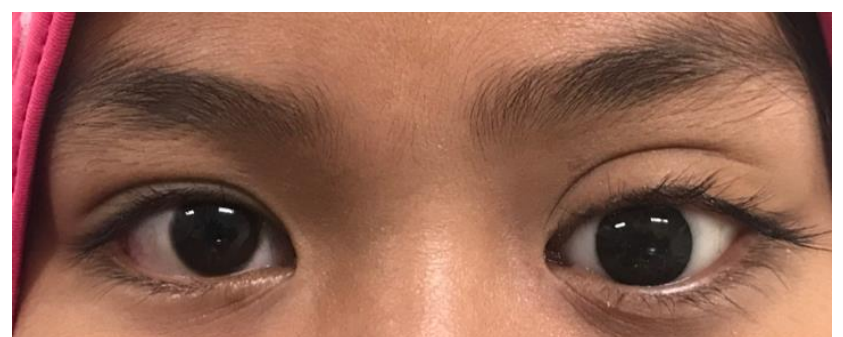

Fig. 11. New acrylic base individual ocular prothesis after insertion.

Ocular prothesis was disinfected in a solution of chlorhexidine for 15 minutes and rinsed in a saline solution before inserted. The prothesis was inserted and checked for any discomfort, retention, stabilization, and harmonization by performing the eye movement like opening, closing and glancing. The removal, placing and how to clean an ocular prothesis was instructed to the patient (Fig. 11)

\section{DISCUSSION}

A custom ocular prosthesis is a good option when reconstruction by plastic surgery or the use of implants is not possible or affordable [1]. Custom made ocular prothesis is better than stock prothesis because it can retain the shape of the socket, prevent the lid from collapsing, provides proper muscle activity, prevent accumulation of eye fluid and debris, and maintain palpebral. Also, it can mimic the colour, shape, size, and movement like natural eye $[8,9]$.

There are many impression techniques which had been reported in literature. In this case we modified impression technique that suggested by Miller and Smith [5]. We modified the existing custom ocular prothesis as a custom tray. Polyvinyl siloxane light body waas used as an impression material because of the viscosity so that it could flow through the entire sulcus and record eye sulcus precisely, hence a proper adaptation and functional movement of the ocular prothesis [3].

The most challenging and critical part in the making of an ocular prothesis is producing the iris colour and positioning the iris to the ideal symmetrical position $[1,10]$. Producing the iris colour as natural as a real eye in this era can be taken by photography [1]. Numerous techniques to determine the iris location have been used such as pupilometer, facial measurement, and ocular locator [10]. The transparent graphic grid method is a simple procedure by modifying the previously described methods for positioning of the iris. The reference points used are both horizontal and vertical lines are marked on the skin, extending through the centre of pupil and used as a better guide in comparing the inner canthus of an eye itself as used previously in literature [10]. The described technique is a simple, practical, and time efficient method of fabricating ocular prosthesis. Nevertheless, stock ocular prosthesis cannot be discredit, since it can be used as an immediate prothesis after surgery or used as an interim prothesis [7]. A well-made and properly planned custom-made ocular prosthesis provides better results functionally as well as aesthetically.

\section{CONCLUSIONS}

A simplified procedure to make an ocular prothesis was described herein. Rehabilitation of ocular defect gave the patient self-confidence and greatly improved the social acceptance. The use of acrylic based individual ocular prothesis provides good aesthetics, retention and stabilization.

\section{REFERENCES}

[1] Lanzara R, Thakur A, Viswambaran M, Khattak A. Fabrication of Ocular Prothesis with Digital Customization Technique- A Case Report. J Family Med Prim care 2019;8:1239-42. pp.

[2] Shenoy K, Sarfaraz H, Dandekeri S, Ragher M, Paulose A, Reshmabanu. A Simplified Approach for Customized Esthetic Acrylic Ocular Prothesis: A Case Report. IJSS Case Reports \& Reviews 2015;1(9):49-51.

[3] Arya G, Kumar N, Aeran H, Seth J. Rehabilitation of Ocular Defect with Custom Made Ocular ProthesisA Case Report. International Journal of Oral Health Dentistry 2017;3(4):225-228.

[4] Agrawal N, Jain D, Gupta A, Jain S. Customize Ocular Prothesis: A Case Report. Journal of Applied Dental and Medical Sciences 2018;4(2):4-6.

[5] Soni S, Singh P, Singh A, Srivastava S, Shekhar A. Ocular Prothesis: Simplified Custom Made Technique- A Case report. Int J Oral Health Med Res 2016;3(1):107-110.

[6] Waskito A, Sugiatno E, Ismiyati T. Protesa Mata: Rehabilitasi Pasien. Maj Ked Gi 2013;20(2):178-83.

[7] Prashanti E, Reddy JM, Vinay K, Mathew X. All about Ocular Prothesis- A Review. Indian Dentist Research and Review 2008;63:53-8.

[8] J.H. Hamissi, M. Esfehani, and Z. Hamissi, "Treatment of Geographic Tongue Superimposing Fissure Tongue: A Literature", Journal of Dental Science, vol. 2, no. 7, pp: 409- 413, 2015.

[9] Shenoy KK, Nag PV. Ocular Impressions: An Overview. The J. of Indian Prosthodontic Society 2007;7:5-7.

[10] Manjita MP, Meena AA Vidya C, Praveen R. Precise Iris Positioning in Ocular Prothesis using an Eyewear. J dental Sci 2017;2(1):121. 